\title{
Validation of Blended Fertilizers Based on Ethio-Sis Soil Fertility Map to Develop Site Specific and Crop at Halaba, Southern Ethiopia
}

\author{
Melkamu Hordofa Sigaye* \\ Ethiopian Institute of Agricultural Research Institute, Wondo Genet Agri. Research Center, Shashemane, \\ Ethiopia.
}

*Corresponding Authors: Melkamu Hordofa Sigaye, hiopian Institute of Agricultural Research Institute, Wondo Genet Agri. Research Center, Shashemane, Ethiopia.

\begin{abstract}
Balanced use of inorganic fertilizers has been the important tools to overcome soil fertility problems and enhance crop production and productivity. The experiment was conducted validate blended fertilizer to develop site and crop specific optimum rate recommendations based on Ethio-SIS soil fertility map in Halaba, southern Ethiopia, during the 2019 cropping season. The experiment was consisted of six treatments levels: (1) control or unfertilized, (2) farmers' practice (100 kg ha-1 of NPSB + $50 \mathrm{~kg} \mathrm{ha}^{-1}$ of Urea), (3) $100 \%$ of the recommended rates of $N$ and $P$ which is-138 $N$ and $92 P$, (4) 50\% of the recommended rates of $N$ and $P$ from blended (NPSB) fertilizer and urea, (5) 100\% of the recommended rates of $N$ and $P$ from blended (NPSB) fertilizer and urea and (6) $150 \%$ of the recommended rates of $N$ and $P$ from blended (NPSB) fertilizer and urea. The treatments were arranged in randomized complete block design with three replications. The result revealed that the maximum grain yield $\left(8,240 \mathrm{~kg} \mathrm{ha}^{-1}\right)$, straw yield $\left(18,435 \mathrm{~kg} \mathrm{ha}^{-1}\right)$ and biomass yield $\left(25,858 \mathrm{~kg} \mathrm{ha}^{-1}\right)$ of maize was obtained from application $150 \%$ of recommended rate nitrogen and phosphorous from NPSB blended fertilizer plus urea source. The economic analysis indicated that the application of $150 \%$ of recommended rate nitrogen and phosphorous from NPSB blended fertilizer and urea source were gives net benefit value of (107113.50 ETB $\mathrm{ha}^{-1}$ ) with MRR of (9\%). These results suggest that an appropriate use balanced fertilizer based on site and crop specific not only provides enough nutrients to the soil but also improves crop production and productivity. There for application of $150 \%$ of recommended rate nitrogen and phosphorous from NPSB blended fertilizer and urea source based on Ethio-SIS soil fertility map can be recommended to farmers for maize producers, that with assurance of economic returns in Halaba, Southerm Ethiopia and areas with similar agroecological and soil conditions. Finally, further investigation should be undertaken across years and different locations to confirm the current finding and for wider applicability.
\end{abstract}

Keywords: Blended fertilizer, Grin yield, Maize, NP and NPSB

\section{INTRODUCTION}

In Ethiopia, agriculture provides an employment to $85 \%$ of the population, contributes $90 \%$ of the total export earnings, supplies over $70 \%$ of the total raw materials required by industries and accounts for $60 \%$ of the country's gross domestic product (CSA, 2016). It plays a great role in Ethiopia's economic development and will expertise the lead for many years to come. Since, Ethiopian agriculture is characterized by low production per unit. One of the major constraints for low crop productivity is low soil fertility, which is exacerbated by soil fertility depletion through nutrient removal with harvest, tillage, weeding, and losses in runoff and soil erosion, soil degradation and nutrient depletion and use of unbalanced and right amount and form fertilizer for site and crop specific (Hussain et al., 2006).

Soil fertility maintenance is a major concern in tropical Africa predominantly with the rapid population increase, which has occurred in the past few decades (Smaling and Braun, 1996). Similarly, Dagne (2016) reported that increasing crop production and soil resources in the smallholder farm sector of Africa has become a vast challenge. Inorganic fertilizers have been the important tools to overcome soil fertility problems and they are also responsible for a large part of the food production increases. The drive for higher agricultural production without balanced use of fertilizers created problems of soil fertility exhaustion and essential plant nutrient imbalances not only of major but also of secondary macronutrient and micro-nutrients. The deficiencies of secondary macro-nutrient and micro-nutrient 
will arise if they are not refilled timely under intensive agriculture (Fageria and Baligar, 2008; Singh, 2011).

Recently, according to the soil fertility map Ethiopia soil analysis data revealed that the deficiencies of most of nutrients such as, nitrogen (86\%), phosphorus (99\%), sulfur (92\%), born (65\%), zinc (53\%), potassium (7\%), copper, manganese, and iron were widespread in Ethiopian soils (Ethio-SIS, 2016). Similarly, Asgelil et al. (2007) reported show that K, S, Ca, Mg, and micronutrients ( $\mathrm{Cu}, \mathrm{Mn}, \mathrm{B}, \mathrm{Mo}$, and $\mathrm{Zn}$ ) were becoming depleted and deficiency symptoms were observed in major crops in different parts of the country. Consequently, to overcome this problem of nutrient deficiency using those soil fertility maps (soil fertility atlas), district level multi-nutrient balanced fertilizers containing N, P, K, S, $\mathrm{B}$ and $\mathrm{Zn}$ in blend form have been issued to ameliorate site-specific nutrient deficiencies and thereby increase crop production and productivity in the areas. Since, experiments on validation of blended fertilizers (formulae) for major crops across different soil types have been conducted throughout the country in comparison with the previous recommended fertilizer rates.

However, blended fertilizers validation studies for major crops and soil types are still limited and information not sufficiently available for low potential parts of the country especially at Halaba district. Moreover, according to soil fertility maps (soil fertility atlas), survey report the deficiency of nitrogen, phosphorous, sulfur, and boron were widely spread in Halaba areas (Ethio-SiS, 2016). Therefore, it is necessary to improve the nutrient content of fertilizer that suits the needs and the productivity of the crop and soil. However, information on the application of rate blended fertilizer NPSB especially for maize was not determined at the study area. Therefore, these particular experiments were designed the following general and specific objectives:

\section{General Objective}

- To enhance crop productivity and contribute for food security

\section{Specific Objective}

- To validate blended fertilizer recommendations (rates) based on Ethio-SIS soil fertility map of the area

- To determine economically optimum blended fertilizer rates for maize production

\section{Materials ANd Methods}

\subsection{Description of the Experimental Area}

The study was conducted during 2019 main cropping season in Halaba, districts of Southern Ethiopia. The geographic locations of the experimental site in Halaba lie $7^{\circ} 24^{\prime} 53.87^{\prime \prime} \mathrm{N}$ and $38^{\circ} 6{ }^{\prime} 55.54^{\prime \prime}$ E at an altitude of $1790 \mathrm{~m}$. a. s. $l$. The major crops growing in the area were maize, wheat, sorghum, barley, tef and pepper. A minimum distance of $500 \mathrm{~m}$ was kept between farmers' fields to catch variability of soil conditions.

\subsection{Experimental Set-up and Procedure}

The experiment was established in a randomized complete block design (RCBD) with three replications. It consisted of 6 treatment levels: (1) control (no input), (2) farmers' practice (100 kg ha-1 of NPSB + $50 \mathrm{~kg} \mathrm{ha}^{-1}$ of Urea) for maize and tef at each district, (3) $100 \%$ of the recommended rates of $\mathrm{N}$ and $\mathrm{P}$ from TSP and urea, (4) $50 \%$ of the recommended rates of $\mathrm{N}$ and $\mathrm{P}$ from blended fertilizer and urea, (5) $100 \%$ of the recommended rates of $\mathrm{N}$ and $\mathrm{P}$ from blended fertilizer and urea and (6) $150 \%$ of the recommended rates of $\mathrm{N}$ and $\mathrm{P}$ from blended fertilizer and urea and ( $\mathrm{BH}-546$ variety) of maize was used. The trial was conducted at 2 farmers' fields and per each crop and a minimum distance of $500 \mathrm{~m}$ was kept between farmers' fields to catch variability of soil conditions.

The blended and phosphorus containing fertilizers from NPS and triple super phosphate (TSP), respectively were basally applied once at sowing to minimize losses and increase use efficiency. The nitrogen fertilizer from Urea was applied in the row in two times; half at sowing and the other half during the maximum growth; between the third and fourth weeks of sowing after first weeding and during light rainfall to minimize $\mathrm{N}$ loss All other agronomic management practices were applied as per recommendation for the variety. The necessary data were collected at right time and crop growth stage. 


\subsection{Data Collection}

The crop yield and yield components collected included grain yield, total above biomass yield, straw yield. Composite soil samples per farmer field were collected at a depth of $0-20 \mathrm{~cm}$ prior to sowing. Soil samples were also collected immediately after harvesting at the aforementioned depth from each plot per farmers' fields for investigating the changes in soil chemical properties due to treatments application. The soil samples were air dried, grounded to pass to $2 \mathrm{~mm}$ sieve, and analyzed for soil texture, $\mathrm{pH}$, organic matter, total nitrogen $(\mathrm{N})$, total sulfur $(\mathrm{S})$, available phosphorous $(\mathrm{P})$, cation exchange capacity (CEC) and boron (B).

\subsection{Economic Analysis}

Economic analysis was conducted to investigate the economic feasibility of the treatments according to the procedure set by CIMMYT (1988). Partial budget, dominance and marginal analysis were carried out. The average yield was adjusted downwards by $10 \%$ to reflect the difference between the experimental plot yield and the yield farmers were expecting from the same treatment. The average open market price (Birr kg${ }^{-1}$ ) for maize and the official prices of each fertilizer were used for analysis.

\subsection{Statistical Analysis}

The data were analyzed by using one-way analysis of variance (ANOVA) using Statistical Analysis Software (SAS) version 9.4, (SAS, 2014). Whenever treatments effects were significant, mean separations were made using the least significant difference $(L S D)$ test at $(p \leq 0.05)$ level of probability test by one-way analysis.

\section{RESUlT AND DISCUSSION}

\section{Soil Physicochemical Properties of the Experimental Sites Before Sowing}

The soil particle size distributions of site were $63.1 \%, 21.3 \%$ and $15.3 \%$ sand, silt and clay, respectively (Table 1). Thus, the soil textural class of the soils of site was sandy loam (USDA, 1998). The $\mathrm{pH}$ value of the soil was 6.1 (1:2.5 soil: water) (Table 1). The soil $\mathrm{pH}$ has a vital role in determining several chemical reactions in influencing plant growth by affecting the activity of soil microorganisms and altering the solubility and availability of most of the essential plant nutrients particularly the micronutrients such as Fe, Zn, B, Cu and Mn (Sumner, 2000).

The analysis result of available $\mathrm{P}$ of experimental site was $11.2 \mathrm{ppm}$. According to Olsen et al. (1954) rating, the status of available $\mathrm{P}$ of site categorized under medium level (Table 1). The organic carbon and total nitrogen content of site were $1.5 \%$ and $0.12 \%$ respectively (Table 1 ). According to (Tekalign, 1991; Don Ankerman, and Richard, 2015) organic carbon of the is rated as low. Likewise, total nitrogen content of site was under medium condition based on (Tekalign, 1991; Berhanu, 1980) classifications. Total sulfur of the soil was $2.8 \mathrm{ppm}$ and ranged low category (Tekalign, 1991; Don Ankerman, and Richard, 2015). Cation exchange capacity of experimental soil was $12.8 \mathrm{meq} 100 \mathrm{~g}$ sample $^{-1}$ which is found at medium (London, 1991; Hazelton and Murphy, 2007) (Table 1).

Table1. Soil physiochemical properties at Halaba prior to sowing

\begin{tabular}{|c|c|c|c|}
\hline Parameters & Value & Rating & Reference \\
\hline Sand $(\%)$ & 63.1 & & - \\
\hline Silt (\%) & 21.6 & & \\
\hline Clay $(\%)$ & 15.3 & & \\
\hline Textural class & \multicolumn{2}{|c|}{ Sandy Loam } & USDA (1998) \\
\hline pH (1:2.5 soil: water) & 6.1 & & \\
\hline Available P $\left(\mathrm{mg} \mathrm{kg}^{-1}\right)$ & 11.2 & Medium & Olsen et al. (1954) \\
\hline Sulfur $\left(\mathrm{mg} \mathrm{kg}^{-1}\right)$ & 2.8 & Low & Don Ankerman and Richard (2015) \\
\hline Total nitrogen $(\%)$ & 0.12 & Low & Tekalign (1991); Berhanu (1980) \\
\hline Organic carbon $(\%)$ & 1.5 & Low & Tekalign (1991) \\
\hline $\begin{array}{l}\text { Cation exchange capacity }(\mathrm{cmol} \\
\left.(+) \mathrm{kg}^{-1}\right)\end{array}$ & 12.8 & Moderate & $\begin{array}{l}\text { London (1991); Hazelton and Murphy } \\
\text { (2007) }\end{array}$ \\
\hline
\end{tabular}

\section{Effects of NPSB Fertilizer Application on the Soil Chemical Properties after Harvest}

The application of NPSB blended fertilizer significantly influenced the available soil P level of the site (Table 2). The maximum available soil $\mathrm{P}$ was obtained from application of $100 \%$ and $150 \%$ recommended N and P from NPSB and Urea sources. The result further showed that effect of 
application of fertilizers on soil reaction $(\mathrm{pH})$ value, sulfur, total nitrogen, and organic matter contents of the soils of experimental site were not significant (Table 2). However, the trend showed that application of $100 \%$ and $150 \%$ RNP from NPSB and Urea sources improved the total S, total N and OC contents of soils.

Table2. Soil physiochemical properties after crop harvest

\begin{tabular}{|l|l|l|l|l|l|}
\hline Treatments & $\mathrm{pH}$ & $\mathrm{Av} . \mathrm{P}(\mathrm{ppm})$ & $\mathrm{S}(\mathrm{mg} / \mathrm{kg})$ & $\% \mathrm{~N}$ & $\%$ OC \\
\hline Control & 5.85 & $12.82^{\mathrm{b}}$ & 1.81 & 0.12 & 1.18 \\
\hline Farmers Practice & 5.57 & $25.88^{\mathrm{a}}$ & 2.43 & 0.11 & 2.01 \\
\hline $100 \%$ of RNP (from TSP \&Urea) & 5.88 & $30.22^{\mathrm{a}}$ & 3.52 & 0.12 & 1.78 \\
\hline $50 \%$ of RNP (from NPSB \& Urea) & 6.22 & $27.60^{\mathrm{a}}$ & 2.52 & 0.10 & 1.81 \\
\hline $100 \%$ of RNP (from NPSB \&Urea) & 6.20 & $32.30^{\mathrm{a}}$ & 3.44 & 0.14 & 2.33 \\
\hline $150 \%$ of RNP (from NPSB \&Urea) & 6.16 & $31.82^{\mathrm{a}}$ & 3.63 & 0.16 & 2.46 \\
\hline CV & 7.2 & 19.8 & 29.4 & 17.1 & 25.5 \\
\hline 1sd @ 0.05 & $\mathrm{~ns}$ & 9.6 & $\mathrm{~ns}$ & $\mathrm{~ns}$ & $\mathrm{~ns}$ \\
\hline
\end{tabular}

\section{Effects of NPSB fertilizers on yield and yield components of maize}

The results obtained from the two farmers' fields were consistent. Thus, combined analysis was conducted. The application of different rates of NPSB blended fertilizer significantly $(p<0.01)$ influenced the measured variables including above ground biomass, grain yield, straw yield, and harvest index of maize. The above ground biomass, grain and straw yields ranged from 11,758-25,858, 3,4218,240 and 8,337-18,435 $\mathrm{kg} \mathrm{ha}^{-1}$, respectively (Table 3). The polled mean analysis revealed that the maximum above ground biomass $\left(25,858 \mathrm{~kg} \mathrm{ha}^{-1}\right)$, grain $\left(8,240 \mathrm{~kg} \mathrm{ha}^{-1}\right)$ and straw $\left(18,435 \mathrm{~kg} \mathrm{ha}^{-1}\right)$ yields were obtained from the application of $150 \%$ of recommended N and P from NPSB blended and Urea fertilizers. Statistically equivalent biomass and straw yield were also obtained from the application of $100 \%$ of recommended N and P from TSP and urea, and 100\% of recommended N and P from NPSB and urea fertilizers (Table 5). The results further showed no significant difference on most yield and yield components between application of $100 \%$ of recommended N and P from TSP and Urea (which is previous recommendation) and $100 \%$ of recommended N and P from NPSB blended and Urea fertilizers (Table 3). The lowest yield and yield components were recorded at the control or unfertilized plot. The application of $150 \%$ of N and P from NPSB blended and Urea fertilizers was higher in grain yield by 36,34 and $21 \%$ compared to the farmers' practice, application of $100 \%$ of recommended $\mathrm{N}$ and P from TSP and Urea, and application of $100 \%$ of RNP from TSP and Urea fertilizers, respectively. The yield advantage relative to the control (unfertilized) treatment was 58\% (Table 3) indicating the depletion of the soil and its strong response to fertilizer application. This is due to the optimum application of $\mathrm{N}, \mathrm{P}$ and $\mathrm{S}$, and their roles in energy provision for seed formation and grain filling. Therefore, balanced fertilizer application based on soil test-crop response is very crucial to enhance soil fertility and crop yield.

Likewise, the application of nitrogen with addition of sulfur nutrient had positive or synergetic effect (Marschner, 2002). This positive interaction could be important in boosting crop yield. Also, sulfur is essential for production of chlorophyll and utilization of phosphorus and other essential nutrients. Sulfur also, ranks equal to nitrogen for optimizing crop yield and quality (Marschner, 2002).

The maize yield depends mainly on the availability of essential plant nutrients from the application of fertilizers (Adediran, et al., 2003). In agreement with the result of this experiment, Dagne (2016) also observed the maximum mean grain yield $\left(8,400 \mathrm{~kg} \mathrm{ha}^{-1}\right)$, straw yield $\left(8,553 \mathrm{~kg} \mathrm{ha}^{-1}\right)$ and total biomass yield $\left(16,868 \mathrm{~kg} \mathrm{ha}^{-1}\right)$ from blended fertilizers, whereas the lowest from the control treatment. Similarly, Abebaw and Hirpa (2018) also reported that application of blended fertilizer at a rate of $200 \mathrm{~kg} \mathrm{ha}^{-1}$ along with $63.91 \mathrm{~kg} \mathrm{ha}^{-1}$ urea gave the maximum tef grain yield as compared to control and recommended nitrogen and phosphorous fertilizer rate.

Table3. Polled means value of biomass yield, straw yield, grain yield and harvest index of maize crop as influenced by different rate of NPSB fertilizer application

\begin{tabular}{|l|l|l|l|l|}
\hline Treatments $\left(\mathrm{kg} \mathrm{ha}^{-1}\right)$ & AGBM $\left(\mathrm{kg} \mathrm{ha}^{-1}\right)$ & SY $\left(\mathrm{kg} \mathrm{ha}^{-1}\right)$ & $\mathrm{GY}\left(\mathrm{kg} \mathrm{ha}^{-1}\right)$ & HI\% \\
\hline Control & $11758.0^{\mathrm{c}}$ & $8337.0^{\mathrm{c}}$ & $3421.3^{\mathrm{d}}$ & $29.2^{\text {abc }}$ \\
\hline
\end{tabular}


Validation of Blended Fertilizers Based on Ethio-Sis Soil Fertility Map to Develop Site Specific and Crop at Halaba, Southern Ethiopia

\begin{tabular}{|l|l|l|l|l|}
\hline Farmers Practice & $19900.0^{\mathrm{b}}$ & $14421.0^{\mathrm{b}}$ & $5479.2 \mathrm{~b}^{\mathrm{c}}$ & $27.4^{\mathrm{abc}}$ \\
\hline $100 \%$ of RNP (from TSP \&Urea) & $23013.0^{\mathrm{ab}}$ & $16494.0^{\mathrm{ab}}$ & $6518.6^{\mathrm{b}}$ & $29.2^{\mathrm{abc}}$ \\
\hline $50 \%$ of RNP (from NPSB \& Urea) & $15433.0^{\mathrm{c}}$ & $10196.0^{\mathrm{c}}$ & $5236.9^{\mathrm{c}}$ & $34.4^{\mathrm{a}}$ \\
\hline $100 \%$ of RNP (from NPSB \&Urea) & $24917.0^{\mathrm{a}}$ & $17619.0^{\mathrm{ab}}$ & $6481.6^{\mathrm{b}}$ & $26.3^{\mathrm{c}}$ \\
\hline $150 \%$ of RNP (from NPSB \&Urea) & $25858.0^{\mathrm{a}}$ & $18435.0^{\mathrm{a}}$ & $8239.5^{\mathrm{a}}$ & $32.2^{\mathrm{ab}}$ \\
\hline CV & 16.7 & 19.1 & 17.1 & 15 \\
\hline lsd @ 0.05 & $3881.1^{* *}$ & $3395.1^{* *}$ & $1181.0^{* *}$ & $5.9^{* *}$ \\
\hline Famer*treatment & $\mathrm{ns}$ & $\mathrm{ns}$ & $\mathrm{ns}$ & $\mathrm{ns}$ \\
\hline
\end{tabular}

Note: AGBM, SY, GY and HI; above ground biomass, straw yield, grain yield and harvest index, respectively.

\section{Economic Analysis}

The result of the partial budget analysis is given in (Table 4). Maize production under NPSB and Urea fertilizer management involved different costs, which affected the total production cost that varied within each treatment. According, to results suggested that all treatments were economically feasible as the net benefit values (NBV) were greater than zero (NBV>0). But the maximum net benefit value (107113.50 $\mathrm{ETB} \mathrm{ha}^{-1}$ ) with MRR of $9 \%$ was obtained from that application of $150 \%$ of recommended $\mathrm{N}$ and P from NPSB blended fertilizer and Urea sources (Table 4) and; these could be the best rate to apply for maize in area for maize producers. However, the minimum net benefit value (44476.90 ETB $\left.\mathrm{ha}^{-1}\right)$ and (71229.60 ETB ha ${ }^{-1}$ ) of were obtained from control and followed by farmers practice respectively.

Table4. Economic analysis for the effect of NPSB blended and conventional NP fertilizers application on maize production at Halaba district.

\begin{tabular}{|l|c|c|c|c|c|}
\hline Treatments & $\begin{array}{c}\text { AGY (kg } \\
\left.\text { ha }^{-1}\right)\end{array}$ & $\begin{array}{c}\text { TVC } \\
(\text { Birr })\end{array}$ & $\begin{array}{c}\text { GFB } \\
\text { (Birr) }\end{array}$ & NB (Birr) & MRR (\%) \\
\hline Control & 3421.3 & 1375.00 & 45851.9 & 44476.9 & -- \\
\hline Farmers Practice & 5479.2 & 3825.00 & 75054.6 & 71229.6 & 10.9 \\
\hline $100 \%$ of RNP (from TSP \& Urea) & 6518.6 & 7325.00 & 92066.8 & 84741.8 & 3.9 \\
\hline $50 \%$ of RNP (from NPSB \& Urea) & 5236.9 & 3911.75 & 71991.5 & 68079.7 & D \\
\hline $100 \%$ of RNP (from NPSB \& Urea) & 6481.6 & 6448.5 & 90709.3 & 84260.8 & 6.4 \\
\hline $150 \%$ of RNP (from NPSB \& Urea) & 8239.5 & 8985.25 & 116098.8 & 107113.5 & 9.0 \\
\hline
\end{tabular}

Note: (1) AGY, TVC, GFB, NB, MRR and D are adjusted grain yield, total variable costs, gross field befit, net befit and marginal rate of return (\%) and dominated, respectively; (2) Price of Urea, TSP and NPSB were $=15.5$, 19 and 16.5 birr $\mathrm{kg}^{-1}$, respectively;(3) Price of maize grain was 13 birr $\mathrm{kg}^{-1}$

\section{CONCLUSION AND RECOMMENDATIONS}

In Ethiopia maize production and productivity have been low mainly due to declining soil fertility, unbalanced application of fertilizer through without soil test based and crop response and use of inappropriate fertilizer recommendations. Based on the study the maximum grain yield $\left(8,240 \mathrm{~kg} \mathrm{ha}^{-1}\right)$, straw yield $\left(18,435 \mathrm{~kg} \mathrm{ha}^{-1}\right)$ and biomass yield $\left(25,858 \mathrm{~kg} \mathrm{ha}^{-1}\right)$ of maize was obtained from application $150 \%$ of recommended rate N and P from NPSB blended fertilizer and Urea sources. The economic analysis also indicated that the application of $150 \%$ of recommended rate $\mathrm{N}$ and $\mathrm{P}$ from NPSB blended fertilizer source gives net benefit values of $\left(107,113.50 \mathrm{ETB} \mathrm{ha}^{-1}\right)$ with MRR of $9 \%$. Therefore, from this study I conclude that application $150 \%$ of recommended rate N and P from NPSB blended fertilizer source was significantly improved maize yield and increases soil fertility by improving some essential soil nutrients at the site. Nevertheless, this is one season result, so further study should be done for two years to confirm and for wider applicability of the current finding.

\section{ACKNOWLEDGMENT}

The author gratefully acknowledges Wondo genet agricultural research center and members of the natural resource management process, who facilitated research work. This study was fully supported (REALISE) Realizing Sustainable Agricultural Livelihood Security in Ethiopia. 


\section{REFERENCES}

[1] Abebaw Tadele Alem and Hirpa Legese. 20118. Effects of fertilizer rate (blended) and sowing methods on yield of bread wheat (triticum aestivum) and its economic profitability in western Ethiopia. Int. J. Compr. Res. Biol. Sci. (2018).5(7):1-14.

[2] Adediran, J. A. and J. O. Kogbe, 2003. Influence of nitrogen, phosphorus and potassium application on the yield of maize in the savanna zone of Nigeria. African J. Biotech. 2: 345-349.

[3] Asgelil D., Taye B., and Yesuf A. 2007. The status of Micro-nutrients in Nitisols, Vertisols, Cambisols, and FLuvisolss in major Maize, Wheat, Teff and Citrus growing areas of Ethiopia. In Proceedings of Agricultural Research Fund. pp 77-96.

[4] Berhanu Debele, 1980. The physical criteria and their rating proposed for land evaluation in the highland region of Ethiopia. Land Use Planning and Regulatory Department, Ministry of Agriculture, Addis Ababa, Ethiopia.

[5] CIMMYT. 1988. From agronomic data to farmer's recommendations: economics training manual. Completely revised edition, CIMMYT, Mexico. D.F. 79 pp.

[6] CSA (Central Statistical Agency). 2016. Agricultural Sample Survey for the crop season. Vol. 5 report on Area and production Statistical Bulletin 578. FDRE/CSA, A.A, Ethiopia.

[7] Dagne C. 2016. Blended fertilizers effects on maize yield and yield components of Western Oromia, Ethiopia. Agriculture, Forestry and Fisheries 5(5):151-162. doi: 10.11648/j.aff.20160505.13.

[8] Don Ankerman, B.S. and Richard Large, 2015 Agronomy Hand book. Soil and Plant Analysis Midwest Laboratories, Inc pp,35.

[9] Ethio-SIS (Ethiopia Soil Fertility Status). 2016. Fertilizer Recommendation Atlas of the Southern Nations, Nationalities and Peoples' Regional State, Ethiopia. pp 81.

[10] Fageria, N. K. and V. C. Baligar. 2001. Improving nutrient use efficiency of annual crops in Brazilian acid soils for sustainable crop production. Commun. Soil Sci. Plant Anal. 32:1303-1319.

[11] Hazelton, P., and B. Murphy, 2007. Interpreting soil test results: What do all the numbers mean $2^{\text {nd }}$ Edition. CSIRO Publishing. 152p.

[12] Hussain N, Khan M.A and Javed M.A. 2006. Effect of foliar application of plant micronutrient mixture on growth and yield of wheat (Triticum aestivum L.). Pak. J. Bio. Sci. 8:1096-1099.

[13] Landon, J.R. 1991. Booker tropical soil manual Hand Book for soil survey and agricultural land evaluation in the tropical and sub tropics. Long man scientific and technical, ESSXEX, New York.474p.

[14] Marschner H. 2002. Mineral nutrition of higher plants .2 ${ }^{\text {nd }}$ ed. Academic Press: London.674p.

[15] SAS (Statistical Analysis System Institute). 2014. SAS Version 9.4 @ 2002-2012. SAS Institute, Inc., Cary, North Carolina, USA.

[16] Singh J, Bisen S, Bora DK, Kumar R, Bera B (2011). Comparative study of organic, inorganic and integrated plant nutrient supply on the yield of Darjeeling tea and soil health. Field Crop Research 58:58-61. Singh NI, Chauhan JS (2009). Response of French bean (Phaseolus Vulgaris L.) to organic manures and inorganic fertilizer on growth and yield parameters under irrigated condition. Natural Science 7(5):1-3.

[17] Smaling, E. M. and A. R. Braun, 1996. Soil fertility research in sub-Saharan Africa: new dimensions, new challenges. Commun. Soil Sci. and Plant Anal. J. 27: 365-386.

[18] Sumner, M.E. 2000. Handbook of Soil Science, CRC Press, Boca Raton, FL.

[19] Tekalign Tadese. 1991. Soil, plant, water, fertilizer, animal manure and compost analysis. Working Document No. 13. International Livestock Research Center for Africa, Addis Ababa, Ethiopia.

Citation: Melkamu Hordofa Sigaye, "Validation of Blended Fertilizers Based on Ethio-Sis Soil Fertility Map to Develop Site Specific and Crop at Halaba, Southern Ethiopia” International Journal of Research Studies in Agricultural Sciences (IJRSAS), 2020; 6(8), pp. 23-28, https://doi.org/10.20431/2454-6224.0608004

Copyright: (C) 2020 Authors. This is an open-access article distributed under the terms of the Creative Commons Attribution License, which permits unrestricted use, distribution, and reproduction in any medium, provided the original author and source are credited. 